\title{
ACREDITACIÓN DE ALTA CALIDAD FACULTAD DE MEDICINA
}

\author{
Sergio A. Parra D. MD*
}

El 8 de agosto de 2012 mediante Resolución No. 9158 del Ministerio de Educación Nacional, el programa de medicina de la Fundación Universitaria de Ciencias de la Salud recibió acreditación de alta calidad por un período de cuatro años. Este reconocimiento nos llena de orgullo y nos sitúa en la élite de los programas de medicina de nuestro país. Recogimos así el fruto de un proceso serio de autoevaluación que comprometió el liderazgo de la decanatura bajo la guía de la oficina de aseguramiento de la calidad, el apoyo irrestricto del Consejo Superior y la participación de la comunidad académica en general. Se asumió de manera integral la evaluación de cada una de las características y factores exigidos por el CNA con el propósito de identificar fortalezas, debilidades y plantear planes de mejora que llevaran al programa de medicina a ser reconocido como uno de alta calidad.

Este proceso se inició en el período 2006-2008 cuando se presentó a consideración del CNA el programa en primera instancia, de donde surgieron las siguientes recomendaciones:

- Mantener las fortalezas para la formación de los estudiantes del programa logradas en las áreas clínicas.

- Fortalecer la planta docente mediante la vinculación de un mayor número de profesores de tiempo completo y medio tiempo e incrementar los niveles de formación de maestría y doctorado.

- Intensificar el desarrollo de la investigación y su incorporación en los procesos de enseñanza aprendizaje del programa; propender por un ma-

* Rector Fundación Universitaria de Ciencias de la Salud. Bogotá DC, Colombia.

- Incrementar la producción académica de los profesores y su difusión en medios indexados.

- Propender por la cualificación permanente, profesional y pedagógica, del cuerpo docente.

- Intensificar el componente de internacionalización en el desarrollo del programa.

- Dar mayor impulso al uso de lenguas extranjeras en el desarrollo de las actividades lectivas del programa.

- Mantener la dinámica en el desarrollo de los planes de acción para el fortalecimiento de la institución y del programa.

Durante el período 2008-2010 se realizaron las siguientes acciones en respuesta a las recomendaciones antes enunciadas: 
- Contratación directa del $60 \%$ de la planta docente y el $40 \%$ a través de sociedades.

- Vinculación del $10 \%$ de tiempo completo, $80 \%$ medio tiempo y tiempo parcial y el $10 \%$ hora cátedra.

- Del $100 \%$ de la planta docente, el $48.3 \%$ se contrató por período anual.

- Se implementó el Centro de Idiomas con cuatro niveles de inglés y con el PET como modelo de evaluación reconocido a nivel internacional.

- Se identificaron y reconocieron 22 grupos de investigación con sus respectivas líneas y publicaciones, dependientes de la Facultad de Medicina.

- Se implementaron el manual de incentivo docente y el reglamento de becas y patrocinios para capacitación docente.

- Se abrió la oficina de Internacionalización para fomentar la movilidad de docentes, estudiantes y la vinculación a redes de apoyo.

- Se ofreció el diplomado en docencia universitaria para el área de la salud, el cual fue tomado en forma masiva por nuestro cuerpo profesoral.

Una vez instauradas estas recomendaciones se diseñó un modelo de autoevaluación basado en los siguientes aspectos:

- Análisis de los referentes institucionales y disciplinares.

- Estructura del modelo de ocho factores y 48 características.

- Ponderación de cada una de las características.

- Recolección de la información de evaluación a estudiantes, profesores, empleadores, administrativos y egresados.

- Análisis de la información.
- Elaboración del informe.

- Calificación.

- Propuestas de mejoramiento.

Este proceso se plasmó en un documento maestro que con sus respectivos anexos se envió el 11 de octubre de 2011 al CNA.

Los días 15, 16 y 17 de febrero de 2012 se recibió la visita de los doctores Liliana Arias y Francisco Henao, evaluadores externos quienes conceptúan: "El programa de Medicina de la Fundación Universitaria de Ciencias de la Salud se ubica en la gradación A "Se cumple plenamente." El equipo de pares reconoce el trabajo de la Institución, reflejado en la aplicación efectiva de Planes de Mejoramiento a nivel Institucional y del Programa. Existen políticas, planes y procesos. Hay compromiso y pertinenciade profesores, estudiantes y personal directivo y administrativo para mejorar continuamente los estándares de calidad. El programa de Medicina de la FUCS cumple plenamente con los lineamientos de calidad establecidos para los programas de Educación Superior".

El resultado entonces es que el programa de medicina de la FUCS es reconocido como uno de alta calidad, lo que nos permite agilizar nuestros procesos para el desarrollo de la Facultad y la Institución ante los entes oficiales.

Sólo me resta agradecer al Consejo Superior, a nuestro Presidente Dr. Jorge Gómez, al rector Dr. Roberto Jaramillo, a la Oficina de Aseguramiento de la Calidad en cabeza de la Dra. Claudia Moreno, a la División de Investigaciones, a los jefes de asignatura, a los docentes, a los alumnos, a los egresados, a todo el cuerpo administrativo, a las unidades de apoyo y a mis compañeros de trabajo directo en la Facultad de Medicina Dr. Gonzalo López y Dr. Álvaro Granados.

A todos ellos un fraternal abrazo y que Dios y nuestro compromiso nos permita disfrutar y mantener este objetivo misional en nuestra Institución. 